\title{
A gendered study of young adult contraceptive use at one university in KwaZulu-Natal
}

\author{
OA Oyedeji, M.A \\ University of KwaZulu-Natal \\ R Cassimjee, M.Cur \\ University of KwaZulu-Natal
}

Keywords:

Gender, contraceptives, young adults

\section{Abstract: Curationis 29(3): 7-14}

This study explores contraceptive use among young adult male and female students (aged 18-25) who visit the campus clinic at a university in KwaZulu-Natal. Both a descriptive survey and face to face interviews were used for data collection.

In this study, it is affirmed that gender stratification, societal attitudes, and misconceptions about contraceptive use play an important role in the attitudes of young adults, male and female towards contraception and its use. Evidence of this is the high use of condoms amongst both male and female students' compared with other available methods. Among female students this was highly attributed to personal convenience and comfort with condom use as an unmarried young woman. It was clear from the data collected that respondents themselves attached some stigma to being associated with the use of contraceptive pills or having to visit the clinic regularly for injections as young unmarried women. Male respondents affirmed the use of the condom, although this was hardly with the view of taking reproductive/contraceptive responsibility, but rather, it was attributed to the function of the condom as a safe sex method that offered protection against sexually transmitted diseases and infections. Also evident from the study was the fact that male respondents felt more comfortable with their sexual functioning than the female respondents. This was easily attributed to the role of societal gender stratification in an individual's life.

\section{Introduction}

This study is based on the understanding that women's reproductive health, rights and choices is of great importance to them as individuals. However, its importance is not restricted to women alone but it is of global importance (Ashford, 2001:2).

In the gendered world, the male-female relationship is the paradigm for all power relationships (Millet, 1970:10). More often than not the male gender takes the lead in making decisions at all levels in society even in matters that concern women. According to MacKinnon (1982:60) gender dimorphism is rooted in the biological differences between members of the male sex and members of the female sex, hence the stereotyping of (gender) roles for members of each of the sexes. In society, women are assigned subordinate roles and they are thought of mostly in relation to their reproductive function which is considered to be their natural/ biological roles. The male gender attempts control of members of the female gender's fertility through the manipulation of their decisions concerning when to/when not to have children. Contraceptive use is one of the ways through which men attempt to control women's bodies and fertility, thereby causing the woman herself to lose control of her body to men to the extent that she is deprived of her humanity (Tong, 1989:72). Radical 
feminism views this control as the most fundamental form of oppression.

The issues involved in the subject of women's reproductive health are greater than merely creating awareness about the use of contraceptives, sex education and safe sex. It is, in reality, about women's bodies and the control thereof. It is about their reproductive lives

and rights and what they are allowed to do with their rights in terms of power relations between them and the male.

When the decisions that concern a person are made by him/herself, that person is able to make the best choices for him/herself and to take responsibility for his/her life. Being able to make the decisions in the issues of one's reproductive health, the control of one's fertility in particular is basic to the empowerment of the individual and central to the emancipation of that individual.

\section{Problem statement}

The problem statement for this research was based on and formulated around the assumption that contraception and its use is one of the ways through which men attempt to control women's bodies thereby causing women themselves to lose control of their own bodies to men, to the extent that she is deprived of her independence (Tong, 1989:60).

This form of patriarchy is represented world-wide by government laws and policies that restrict production and availability of adequate forms of contraception to the users. Also on a dayto-day basis, this form of patriarchy is represented by male authority in individual women's lives that affect their choice and use of contraception. Men manipulate the woman's use of contraceptives to benefit them, such that they, the male, and not necessarily the user, are able to control the woman's fertility and sexuality, through her choice, use or non-use of contraception (Firestone, 1972:70).

\section{Research objectives}

The objectives of this study were:

1. To find out how women and men view contraceptive use

2. To ascertain whether contraceptives have a liberating effect on young men and women as a form of reproductive technology

\section{Literature review}

\section{Feminist theories on}

\section{contraceptive use}

Firestone is of the opinion that patriarchy is rooted in the biological inequality of the sexes. It would only be possible to eliminate all sexual roles of masculinity and femininity when humans (women in particular) abandon patriarchal reproduction (Firestone, 1972:74-5). However, some radical feminists argue that female biology in itself is not the cause of woman's oppression but rather, man's control of that biology (O'Brien, 1983; Tong, 1989:78).

Man's attempt to control the female body takes place through various means. Some of these are: contraception, abortion laws, sterilization, or the various forms of violence directed against women (Tong, 1989:80). O'Brien (1983:38) echoes the concern that patriarchy as a system aims to have total control over the female gender by gaining control of women's bodies, reproductive lives and organs, the only aspect of the female gender over which the male gender does not have natural control. Thus, contraception as a form of reproductive technology, is regarded as a means through which men attempt to control a part of life over which they do not naturally have control. This comes in the form of a range of direct or indirect outside influences that affect contraceptive decision-making for women. Some of these are: cultural and societal norms, limited information available, access to contraceptive services and government laws and polices (Population Reports, 2001:3). An indirect way through which men (patriarchy) can gain control of women's lives and reproductive freedom through contraception is when governmental laws that affect women's ability to make independent decisions are made. More direct control is gained through the making of policies that regulate access to information through the media, sex education and health literacy, and limit access to contraceptive supplies and services (Catino, 1999:190; Correa, 1994:25). Women's attempt to control the reproductive process is through the contraceptive industry, regulating their fertility and planning when to or not to get pregnant and by making the choice of which contraceptive method to use and when to use it.

This raises issues of access to and availability of contraception, variety of available contraceptives and the effects of particular methods on the user. On the long run, a woman who is a contraceptive user might thus not necessarily be making a choice, but she might have to use what she finds, what is available, irrespective of what it might be (Correa 1994:20; Population Reports, 2001).

\section{Young adults' use of contraceptives}

Unwanted adolescent pregnancies are of worldwide concern, and this is by no means less among young South African adults. The South African Demographic and Health Survey 1998, showed that sexual behavior starts among boys at around 13 years of age, and around 15 years of age among girls (South African Demographic and Health Survey, 1998:7; Jacobs, 2002:3). The Director-General of Health, South Africa, in 1999 identified teen pregnancies as one of the most critical public health problems in South Africa. By the age of 19 years, 35 percent of all teenagers have been pregnant or have had a child. This represents a very high level of teenage fertility, a continuing source of concern to the government and researchers. According to the South African Demographic and Health Survey 1998, Teenage pregnancy is more prevalent among Colored and rural African girls. The latter groups still experience some form of oppression when it comes to the use of contraceptives (Skewyiya, 2002: 2).

The use of contraceptives among young adults is low (Boult \& Cunningham, 1991:3; Jacobs, 2002:5). In a study carried out among teenagers in Urban South Africa it was discovered that male participants considered contraceptive use to be their partner's responsibility showing that South African youths do not consider contraceptive use or practice to be the responsibility of all partners involved, irrespective of gender (Mfono, 1998:2). This is due to such factors as; social and cultural misconceptions about contraceptive use, lack of independent decision-making power, lack of information, negative attitudes towards contraception and young users.

\section{Methods of contraception available at the study site}

At the campus clinic's contraceptive services are available and offered to students studying at the university. Apart from the initial and mandatory five rand 
each student has to pay prior to any consultation, contraceptive services are provided free of charge. Methods of contraception available at the student clinic can be categorized into three forms, the barrier method, under which fall the condom, injectables and oral contraceptives; Depo Provera and Nur Isterate; every day pills (known as the Pill) and the morning after pill. These are available at the clinic with consultation. Both male and female condoms are available at the clinic. The male condoms are placed in dispensers and are totally free as students can just walk into the clinic and pick them up without paying the consultation fee of five rand. However the female condoms (femidoms) are available with consultation and only on request. On speaking with one of the nurses, it was found out that these are less used by the students so that demand for them is less. Consequently, production rate is much less than that of the male condom. The reason for the choice of this method (femidoms) among this set of students being less can firstly be based on availability, and accessibility as discussed above. Secondly, the nurse disclosed that clients who try them complain that they are uncomfortable to use, they are apparently, not as easy or convenient to wear as the male condom, hence, the female claim to the male condom as their personal method of contraception as will be observed in the findings. The claim to the use of this male method/device (male condom) by the female population raises questions from a gendered perspective. As the male population also view the (male) condom as their arena, something that is worn and should be carried by them. This shows that women are moving into the former male-only zones, taking the tool which men view as theirs, and holding on to it thus taking responsibility for male gender. Also by doing this, the female gender give themselves a voice in an issue that is considered to be the male population's, as the male still has to take responsibility for the utilization of the method thus, women take charge of their sexual lives. Therefore, this can be interpreted as an attempt by women to control and gain power over their reproductive lives, thus resulting in a power struggle between both genders.

Contraception can either be a tool through which women are oppressed by societal and patriarchal constraints, or a tool through which they achieve sexual and reproductive emancipation.
However, in order for contraception to serve as a means or tool of emancipation from sexual and reproductive miseries for women, there is a need for the present patriarchal status of society to be deconstructed and for present negative perceptions and societal mindsets to be done away with.

Of equal importance is the fact that women young and old need to be informed, and encouraged by society to take charge of their individual lives and pertinent issues that concern them. This is imperative not just for the emancipation of the individual (woman), but as the state of women's reproductive health affects the world's population, maternal and child mortality rates, and even the spread of sexually transmitted infections (STI's) among which is the much-dreaded HIV/ AIDS (Ashford, 2001:5).

\section{Setting of the study}

The setting of the study was the campus clinic, of a prominent University in KwaZulu Natal. The target population for this study consisted of Black South African students, both male and female aged between 18 and 25 years.

The clinic is staffed by three registered nurses and one administrative assistant. The clinic has a clientele of approximately 70 students per day. Their consulting hours are between $08 \mathrm{~h} 00-12 \mathrm{~h} 00$ and 14h00-15h00 Mondays to Thursdays and $08 \mathrm{~h} 00$ to $12 \mathrm{~h} 00$ on Fridays.

\section{Research method}

The researcher triangulated two methods. Triangulation uses "measurements from several vantage points and it supports comparison, allowing the phenomenon to be identified" (Thomson,1997:186). This, the researcher did by making use of two different data collection tools. In doing this, the researcher was able to confirm the results derived from one method with the other.

\section{Quantitative methods}

This was done through a descriptive survey which used a structured close ended questionnaire for data collection. The development of the instrument was supervised by two lecturers from the Schools of Nursing and Gender Studies. The reviewed literature and the research objectives where used to develop the questionnaire. The questionnaires were piloted on three students who were part of the research population but they were not included in the sample. The results were positive as the students understood the questions and presented appropriate responses.

The questionnaires were distributed to the first 40 students who fitted the age and gender profile of the study and who agreed in writing to participate. The researcher visited the university clinic daily, between $08 \mathrm{~h} 00$ and $12 \mathrm{~h} 00$ for two weeks, until the required sample number was reached. The researcher distributed the questionnaires to the students after reading the letter of permission.

\section{Development of the instrument}

A semi-structured self-administered questionnaire was developed to collect the data.

The questionnaire was designed by the researcher, and was influenced by the objectives of the study and the reviewed literature.

There was a section of a demographic data which consisted of the following variables: age, gender, marital status, level of education. This information gave valuable comparisons amongst the participants. This was followed by closeended questions on the person's knowledge of contraception, own contraceptive practices, their satisfaction with their choice of contraception. The students were also asked to comment on the frequency, adequacy and arrangement regarding their contraceptive use.

\section{Qualitative Instrument}

The results from the questionnaire proved that the information was superficial and while students talked of important issues around their use of contraceptives, the questionnaire did not allow for the use of this valuable information. Thus, the researcher decided the follow up the data with a semi structure one-to-one interview. The interview included the participant's gender and age. The venue, date and time of the interview was also recorded. There were four open ended questions which focused on the participant's opinion of contraception. The researcher asked if the use of contraceptives was liberating! The researcher also asked who in the relationship kept the condom.

Interviews were conducted among twenty respondents. Ten of them were male, and the other ten were female students respectively. These twenty students were chosen (by verbal and 
written agreement) from the forty respondents who participated in the quantitative research process. They were conducted in a separate room provided by the head nurse at the clinic. Each interview was recorded on a tape, and each respondent's answer was later transcribed onto individual interview sheets for data analysis.

\section{Reliability and Validity}

The instrument was tested for reliability as two experts in nursing research and two family planning nurse practitioners who assessed it for content validity. This was tested against the research objectives. The validity of the instrument was tested by a pilot study where the tool was given to two senior students from another tertiary institution. They managed to complete the instrument in the required time and the results were in keeping with the aim of this research.

\section{Trustworthiness}

In this study, an ad hoc form of analysis was used. According to Kvale (1996:204), in ad hoc analysis there is no standardised method of analysing the whole of the interview material. It is a method of free interplay of techniques during the analysis. Trustworthiness is composed of four main aspects which will be discussed separately. Credibility means being authentic to the data. To achieve this, the researcher utilized a debriefing session which involved discussing the process of data analysis with the researcher's supervisor. The data and categories that were discovered were also discussed with the researcher's supervisor at the regular intervals. Secondly, the researcher used triangulation which refers to the use of different methods of data collection to enhance the credibility. The triangulation was achieved by the use of one to one interviews, and a questionnaire. The researcher played the tape back to the participants and read her written notes back to them so as to validate accuracy of information given and recorded.

\section{Ethical considerations}

Written permission to conduct the study was obtained from the Head of Nursing, Gender Studies, and the campus clinic. Permission to conduct the interviews in the clinic was granted. The researcher requested permission to carry out the research students. The purpose of the study and the procedure of data collection were explained to the
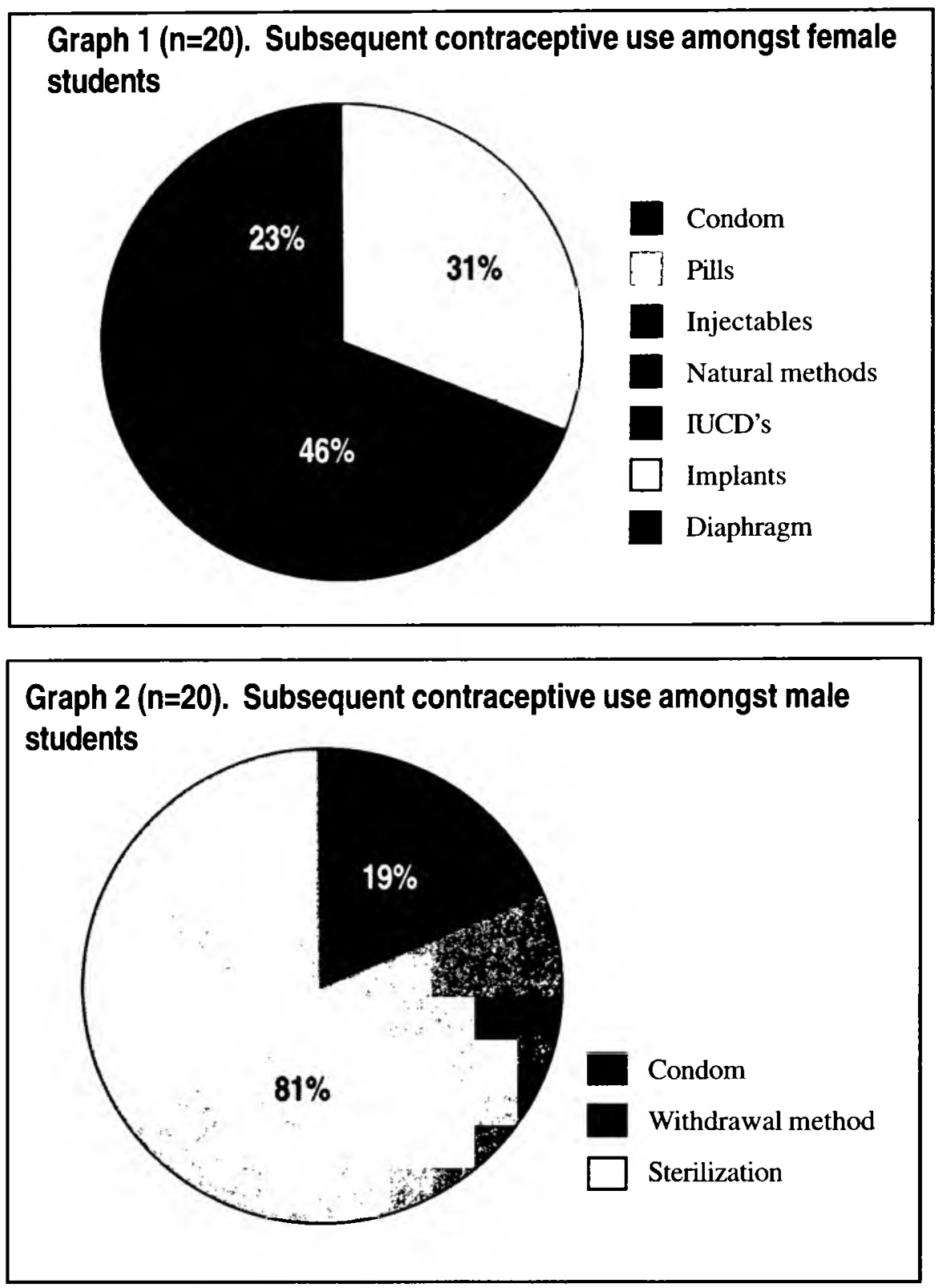

respondents, and they were assured that, the data would be kept anonymous as they were not required to write their names on the questionnaire. Their permission for taping the interview was obtained. Their participation was purely voluntary ant they where given the freedom to withdraw from the study at any time. The researcher explained the right to refuse to answer any question and explained that their confidentiality would be maintained. This was done to encourage the respondent's independent decision making.

The interview was conducted in English as this is the official medium at the study site. During the interview session the researcher ensured privacy and confidentiality by having private interviews on a one on one basis. The students were given letters of explanation and their informed consent was obtained in writing. The researcher introduced herself to the participants and explained her objectives.
The participants were given opportunities to ask questions about the research procedure and the purpose, before giving consent to be part of the research study.

\section{Discussion of the research findings}

The response rate was 100 percent (20 male and 20 female $n=40$ ), as the researcher distributed and collected them herself. The students' ages ranged from eighteen to twenty five and this is in keeping with the average university age.

Graph one and two show that there is an even spread of use of the different contraceptive methods available at the clinic and it also showed that the condom is the preferred method amongst males and females.

Graph two shows that condom use among male students is eighty-one 
written agreement) from the forty respondents who participated in the quantitative research process. They were conducted in a separate room provided by the head nurse at the clinic. Each interview was recorded on a tape, and each respondent's answer was later transcribed onto individual interview sheets for data analysis.

\section{Reliability and Validity}

The instrument was tested for reliability as two experts in nursing research and two family planning nurse practitioners who assessed it for content validity. This was tested against the research objectives. The validity of the instrument was tested by a pilot study where the tool was given to two senior students from another tertiary institution. They managed to complete the instrument in the required time and the results were in keeping with the aim of this research.

\section{Trustworthiness}

In this study, an ad hoc form of analysis was used. According to Kvale (1996:204), in ad hoc analysis there is no standardised method of analysing the whole of the interview material. It is a method of free interplay of techniques during the analysis. Trustworthiness is composed of four main aspects which will be discussed separately. Credibility means being authentic to the data. To achieve this, the researcher utilized a debriefing session which involved discussing the process of data analysis with the researcher's supervisor. The data and categories that were discovered were also discussed with the researcher's supervisor at the regular intervals. Secondly, the researcher used triangulation which refers to the use of different methods of data collection to enhance the credibility. The triangulation was achieved by the use of one to one interviews, and a questionnaire. The researcher played the tape back to the participants and read her written notes back to them so as to validate accuracy of information given and recorded.

\section{Ethical considerations}

Written permission to conduct the study was obtained from the Head of Nursing, Gender Studies, and the campus clinic. Permission to conduct the interviews in the clinic was granted. The researcher requested permission to carry out the research students. The purpose of the study and the procedure of data collection were explained to the

Graph 1 ( $n=20)$. Subsequent contraceptive use amongst female students

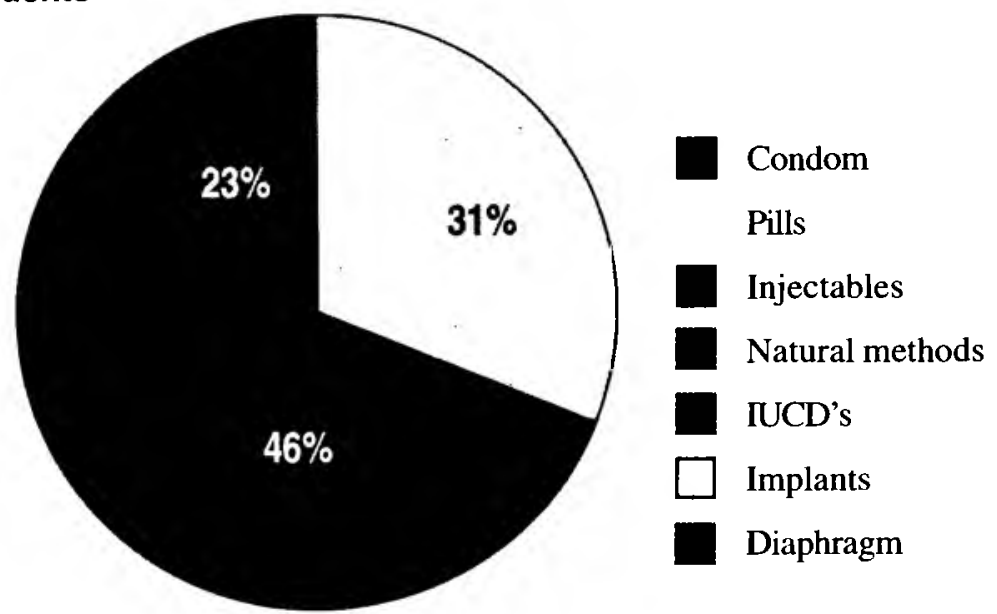

Graph $2(n=20)$. Subsequent contraceptive use amongst male students

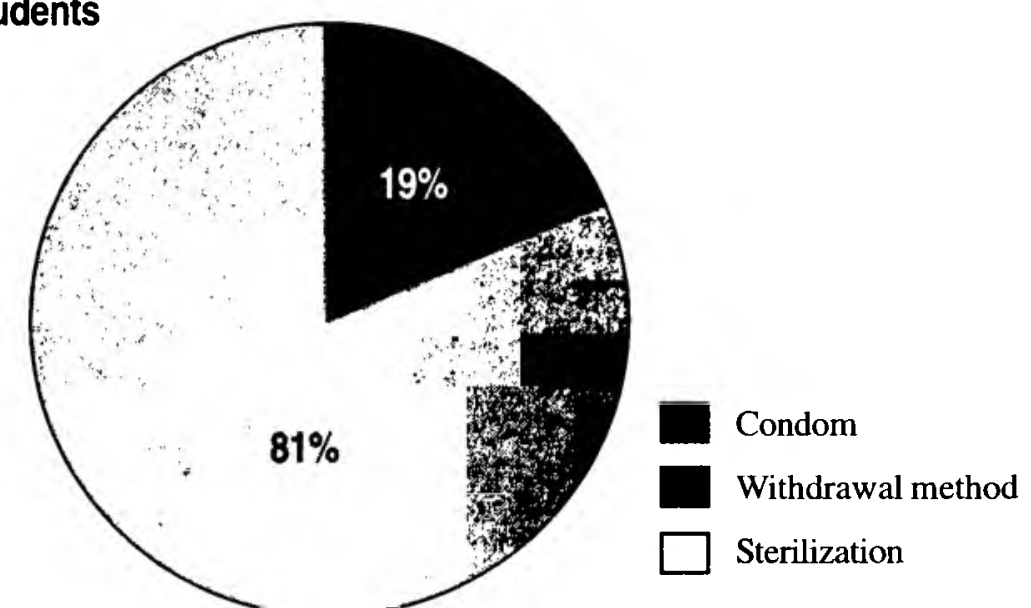

respondents, and they were assured that, the data would be kept anonymous as they were not required to write their names on the questionnaire. Their permission for taping the interview was obtained. Their participation was purely voluntary ant they where given the freedom to withdraw from the study at any time. The researcher explained the right to refuse to answer any question and explained that their confidentiality would be maintained. This was done to encourage the respondent's independent decision making.

The interview was conducted in English as this is the official medium at the study site. During the interview session the researcher ensured privacy and confidentiality by having private interviews on a one on one basis. The students were given letters of explanation and their informed consent was obtained in writing. The researcher introduced herself to the participants and explained her objectives.
The participants were given opportunities to ask questions about the research procedure and the purpose, before giving consent to be part of the research study.

\section{Discussion of the research findings}

The response rate was 100 percent (20 male and 20 female $n=40$ ), as the researcher distributed and collected them herself. The students' ages ranged from eighteen to twenty five and this is in keeping with the average university age.

Graph one and two show that there is an even spread of use of the different contraceptive methods available at the clinic and it also showed that the condom is the preferred method amongst males and females.

Graph two shows that condom use among male students is eighty-one 
percent ( $\mathrm{n}=17)$, while among female students it is forty-six percent $(n=12)$. Among male students, the use of other methods (withdrawal) is nineteen percent $(n=4)$. While female students use of other methods (pill and injectables), is at fiftyfour percent. However, the drop in condom use among female respondents does not necessarily affect female contraceptive use, as the female claim to the use of the male condom was earlier questioned. Meaning that since the male and not the female gender personally takes responsibility for the use of the (male) condom, and the use of the methods for which responsibility is taken by the female gender falls above fifty percent further makes the rise or fall in female condom use inconsequential. Both male and female contraceptive use (of methods that pertain to them) fall above fifty percent, it can be concluded that both take responsibility for contraceptive use. From the qualitative research however, among female respondents the belief is that women take the responsibility while male respondents were of the opinion that men take responsibility for the use of contraception. The latter may be true as this belief is based on the fact that men use the condom, a method that the higher percentage among female respondents, claim to use, meaning that women as well as men, personally take responsibility for condom use. However, an attempt could be made at explaining this results by concluding that the high use of the condom among the male population is by virtue of its functioning as a safe sex method, and not necessarily because of its capacity as a male contraceptive. Eighty-two percent of South African men who participated in a survey said that they would prefer to use a vaginal microbicide rather than condoms for preventing sexually transmitted infections (STIs). Also, most men would like a product that prevents STI's only rather than one that acts only as a contraceptive (Ramjee,2001:7). However, in order to find out more exact statistics on who takes the most responsibility for contraceptive use, more in-dept research would need to be carried out.

\section{Satisfaction with contraceptive use}

Table One shows that majority of the males were content with the male condom (77\%) and withdrawal methods (75\%). Sterilisation was not an option for many
Graph $3(n=40)$. A synopsis of contraceptive use amongst male and female students

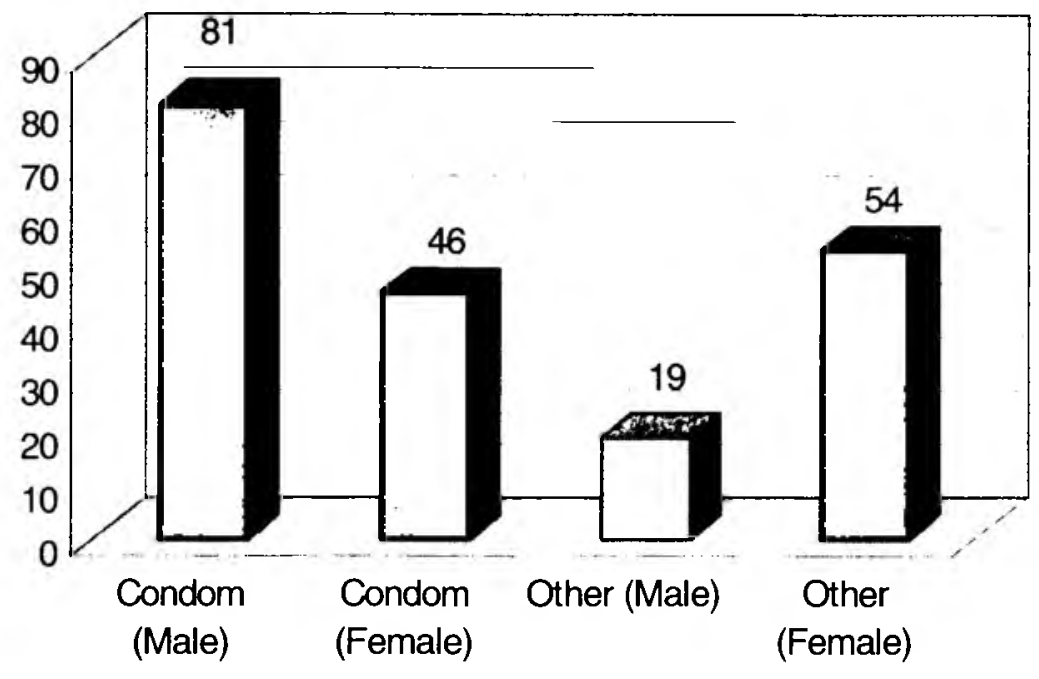

of the respondents. This could be due to the fact that they are young and still not through their reproductive years. Graph Two shows that $85 \%$ of the female respondents who used the male condom as a method of contraception where satisfied with their choice, while all females who used the pill were satisfied with their choice. The participants were asked whether or not they were satisfied with the method of contraception they used. Twenty-four percent $(n=5)$ and fifteen percent $(n=4)$ of male and female respondents respectively, however divulged that they were dissatisfied.

University students could be perceived to be an empowered sector of the population, so it stands to reason that their needs are sorted out independently and therefore are met! The interviews conducted, also confirm that their needs were being met and interests well protected.

From the responses given, the needs and interests of both male and female contraceptive users revolve around safety and protection against unwanted or unplanned for pregnancy and STIs especially, HIV/AIDS. For example, a participant stated, 'I have to use it (condoms) because it's our responsibility, so she (girlfriend) doesn't get pregnant and we reduce the risk of infections.'

Given that the condom serves both sexes, some females but especially male respondents could not or did not see a need to separate the function of the condom as a form of contraceptive, from its function as a safe sex method. Most male respondents thought of the duality of the condom in terms of setting it aside as a contraceptive method for females, and a safe sex method for themselves, and partners. Only a few of them thought

\section{Table $1(n=20)$. Male satisfaction with choice}

\begin{tabular}{|l|l|l|l|l|l|}
\hline Method & Number of Respondents & Yes & \% & No & $\%$ \\
\hline (Male) Condom & 17 & 13 & 7 & 4 & 24 \\
\hline Withdrawal method & 4 & 3 & 75 & 1 & 25 \\
\hline Sterilization & 0 & 0 & & 0 & \\
\hline TOTAL & N/a & $\mathbf{1 6}$ & & $\mathbf{5}$ & \\
\hline
\end{tabular}

- Note: In the questionnaires, the respondents were allowed to choose as many contraceptive options as were pertinent to them. Meaning that each contraceptive method has an overall number of 20 respondents who could have marked it as their method of choice. 
Table 2 ( $n=20)$ Female satisfaction with choice

\begin{tabular}{|l|l|l|l|l|l|}
\hline Method & Number of Respondents & Yes & $\%$ & No & $\%$ \\
\hline (Male) condom & 12 & 10 & 83 & 2 & 17 \\
\hline Pills & 6 & 6 & 100 & 0 & 0 \\
\hline Injectables & 8 & 6 & 75 & 2 & 25 \\
\hline Implants & 0 & 0 & & 0 & \\
\hline IUCD's & 0 & 0 & & 0 & \\
\hline Natural methods & 0 & 0 & & 0 & \\
\hline Diaphragm & 0 & 0 & & 0 & \\
\hline TOTAL & Na & 22 & & 4 & \\
\hline
\end{tabular}

NOTE

Note: In the questionnaires, the respondents were allowed to choose as many contraceptive options as were pertinent to them. Meaning that each contraceptive method has an overall number of 20 respondents that could have marked it as their method of choice.

Table $3(n=20)$. Male knowledge of contraceptive methods for men

\begin{tabular}{|l|l|l|l|l|}
\hline $\begin{array}{l}\text { Number of methods } \\
\text { known }\end{array}$ & $\begin{array}{l}\text { Questionnaire } \\
\text { respondents }\end{array}$ & $\begin{array}{l}\text { Q\& Interview } \\
\text { respondents }\end{array}$ & Total & Percentages \\
\hline One method & 3 & 6 & 9 & $45 \%$ \\
\hline Two methods & 4 & 3 & 7 & $35 \%$ \\
\hline None & 3 & 1 & 4 & $20 \%$ \\
\hline
\end{tabular}

of its contraceptive functions in regard to themselves.

The most obvious reason for this is because the female gender carries the pregnancy.

Based on the above male and female understanding of their biological reproductive functioning, hence, their contraceptive needs, and interpretation of contraception in relation to their respective needs, both male and female users consider their needs as being met, and their interests adequately looked after. However, if despite male respondents understanding of their needs, they have condoms made available to them solely for contraceptive purposes or, other method(s) of contraception, perhaps then, male respondents might be less satisfied with service provided by the condom as there would have been a remarkable change in their perspective.

\section{Recipients' knowledge of available contraceptive choices for men, in comparison to those available for women}

From Table Four it is apparent that male respondents have more knowledge of male contraception than female respondents. The highest percentages found are among female respondents who do not know of male contraception, and male respondents, who know of one method of contraception. Thus, it can be concluded that female male contraceptive knowledge among these set of students is quite low.

The results of the quantitative study, shows that all the respondents were aware of contraception for women. Fortyfive percent $(n=9)$ of male and thirty percent $(n=6)$ of female respondents claimed to know of only one method of contraception available to men. While among male respondents thirty-five percent $(n=7)$ and fifteen percent $(n=3)$ female respondents claimed to know of two methods. Also, twenty percent $(n=4)$ and fifty-five percent $(n=11)$ of male and female respondents respectively, claimed no knowledge of contraception available to men.

It was observed during the research process that there exist attitudes of secrecy towards discourse about issues that are of a sexual nature among some of the young women interviewed. While among young men of the same age group, signals and responses given off when issues of such sexual nature are broached, are quite the opposite. Male respondents seemed visibly pleased about discussing such issues. This is a function of cultural beliefs, societal norms gender stratification, and stereotypes of gender roles and expectations in societies. This more often than not stems from gender dichotomy and patriarchal systems that exists within societies.

\section{Contraceptive use as a form of liberating reproductive technology}

Among research respondents, it was observed that female respondents identified themselves most frequently and easily with contraception and its use. Few male respondents also did this, but the higher number of male respondents identified it with the female gender, they talked about it in relation to members of the female gender getting pregnant and not in relation to themselves causing or bringing about pregnancy in a member of the female gender. Hence, it could be said that members of the male gender designate contraception and its use to be a female arena, which could be both liberating and at the same time unliberating. Liberating in the sense that women are able to make their choices when this happens, enabling them to have total and independent control of their fertility. However, it could be unliberating given that members of the male gender hence take no reproductive responsibility thus reinforcing Mfono's assertion that male participants consider contraceptive use to be their partner's responsibility thus indicating that among South African youths, an attitude of joint responsibility for contraceptive practice is not present (Mfono, 1998:4).

Quantitative research results show that both male and female respondents equally view the use of contraception by 
Table Four ( $n=20)$ Female knowledge of contraceptive methods for men.

\begin{tabular}{|l|l|l|l|l|}
\hline $\begin{array}{l}\text { Number of methods } \\
\text { known }\end{array}$ & $\begin{array}{l}\text { Questionnaire } \\
\text { respondents }\end{array}$ & $\begin{array}{l}\text { Q\& Interview } \\
\text { respondents }\end{array}$ & Total & Percentages \\
\hline One method & 3 & 3 & 6 & $30 \%$ \\
\hline Two methods & 1 & 2 & 3 & $15 \%$ \\
\hline None & 6 & 5 & 11 & $55 \%$ \\
\hline
\end{tabular}

males and females respectively, as acceptable. However, this assertion derived from the quantitative sample is disputed through the course of the qualitative research process and observations, which pass across that male respondents find it hard to identify contraception as a reproductive technology which serves or is meant to serve them. Female respondents however, easily recognize the contraception as such.

One can therefore conclude that members of both the male and female genders identify with contraception as an organization, and as reproductive technology that functions most actively for members of the female gender.

\section{Contraception as a form of reproductive technology, who benefits?}

From the above, the answer to this question would be the individual who uses contraceptives and considers it to be of benefit to them as a form of reproductive technology. However, we may want to refer back to the issue raised by female respondents, as mentioned earlier. This is the possibility of contraceptive use resulting in unprotected sex and probably more frequent unwanted sex. It may also lead to inability of a female partner to say no to unwanted sex especially in sexual relationships. This response was derived from some of the female respondents, 'I find it liberating because I know I cannot fall pregnant when I sleep with my boyfriend. But sometimes it can have a bad effect, because you now don't have an excuse, because he (boyfriend) now knows you won't fall pregnant. Before maybe you'll just say you're not safe but now if I say (lying to boyfriend) I missed my injection, he gets upset because now I'm not safe and, sometimes the condom is uncomfortable.

Even though the above respondent answered in the affirmative to the question, through the response, the respondent confirms that the use of contraceptives might have negative, un-liberating consequences for some women. This then questions the possibility of an individual to be sexually and reproductively liberated due to the use of contraception. However, as we must depend on the data collected, it can be said then that contraception as reproductive technology does benefit the individual who makes use of it. However, from the above we infer that contraceptive use also takes control out of the hands of the females in relationships, since they are obliged to have sexual relations, due to the fact that they are "covered and protected".

\section{Conclusion}

The results derived from this study, imply that male and female respondents are willing to take responsibility for contraceptive use, if they are enlightened and given proper and adequate information about contraception, its functioning, usage and methods. The hormonal contraceptive industry serves the female population more than it does the male, it therefore concludes that hormonal contraception, as a form of reproductive technology serves the female population. Also, from this, one can conclude that the male respondents, need to have an understanding of contraception in general, and how it affects them as individual males, and also in relation to how it affects women.

There are still stereotypes and to break down negative attitudes towards young women's use of contraception. Certain beliefs about and attitudes towards the use of contraception among young adult women results in breeding secrecy, and lack of use among this population while its use may result in bringing down mortality and morbidity rates among young adults. Presently, members of society, both male and female, view the contraceptive industry as a female institution. This could be seen, as an advantage as it suggests that the female population are taking responsibility for themselves, and the male population are admitting that contraception as a form of reproductive technology is something that is essential and needful for the female gender. It also suggests that the male population is willing to relinquish the power to the female gender, to take charge of their sexual and reproductive health. However, despite the fact that women personally suffer for irresponsible sexual behavior, in terms of pregnancies, health and reproductive issues nevertheless affect all people and should be treated accordingly, and accompanied by a sense of responsibility by members of both genders.

Efforts could be made at involving the male population in contraceptive practice through enlightenment programs, and the provision of more methods pertinent to them. Gender stereotypes and patriarchal beliefs and systems in societies that relegate the female gender, confining them to, and prescribing roles of silence, unassertiveness, dependency and subordination to them must be deconstructed.

\section{Limitations of the study}

Using a university student population for this study may be a limitation as they are an empowered group of people with freedom of choices. So one may argue that they are free from oppression and forced decisions. However, even among this set of people, evident from the study is that as young people living within the society, they are nonetheless affected by societal expectations of gender and socio-cultural roles, and these are the factors that help in shaping people/ individuals as members of particular societies.

\section{BIBLIOGRAPHY}

ASHFORD, SL 2001: New Population Policies: Advancing Women's Health Rights. Population Bulletin. 56(1): Washington: Population Reference Bureau.

\section{BOULT, B \& CUNNINGHAM, P 1991:} Black Teenage Pregnancy in Port Elizabeth. Port Elizabeth: Institute for Planning Research.

CATINO, J 1999: Meeting the Cairo 
Challenge: Progress in sexual and reproductive health. Implementing the ICPD Programme of Action. New York: Family CARE International. 190-193

CORREA, S 1994: Population and Reproductive Rights: feminist perspectives from the South. London: Zed.

FIRESTONE, S 1972: The Dialectic of Sex. New York: Morrow Quill (Paperback).

JACOBS, E 2002: Today's virgins, tomorrow's Aids victims. http:// www.impactaids.org.uk/news/pages/ IOL25-10.htm Daily News. Date accessed, August 22003.

KVALE, S 1996: Inter Views: An introduction to qualitative research interviewing. Thousand Oaks, CA: Sage.

MACKINNON, C 1982: Feminism, Marxism, Method and the State: An Agenda for Theory: An Agenda for Theory. Journal of Women in Culture and Societv. 7(3):58 -64.

MFONO, $Z$ 1998: Teenage Contraceptive Needs in Urban South Africa: "A Case Study". The Alan Guttmacher Institute http:// www.agiusa.org/pubs/journals/ 2418098.html (accessed August, 2003).

MILLET, K 1970: Sexual Politics. London: Virago Press.

O'BRIEN, M 1983: The Politics of Reproduction. London: Routledge \& Kegan Paul.

POPULATION REPORTS, 2001: Informed Choice in Family Planning: "Helping people decide". Population Information Program, Series J,:50-54.

RAMJEE, G 2001: The acceptability of a vaginal microbicide among South African men. The Alan Guttmacher Institute's Journal: International Family Planning Perspectives. (Accessed July 2003).

SOUTHAFRICAN DEMOGRAPHIC AND HEALTH SURVEY, 1998: Adolescent Health http:// www.doh.gov.za/facts/1998/ado.html (accessed, September 2002).

SWEWYIYA, Z 2002: Speech at the joint fertility seminar. Department of Social development. Human Science Research

Council : Midrand

THOMSON, $S$ 1997: Nurse teachers as researchers. A reflective approach. Hodder Headline Group. London: Euston Road

TONG, R 1989: Introduction to Feminist Thought. London: Unwin-Hyman. 